\title{
Overlapping Holoprosencephaly-polydactyl syndrome and Asphyxiating thoracic dystrophy, an incidental finding in prenatal ultrasound screening: A rare case report
}

Senai Sereke ${ }^{1}$, Anthony Oriekot ${ }^{1}$, and Felix Bongomin ${ }^{2}$

${ }^{1}$ Makerere University Faculty of Medicine

${ }^{2}$ Gulu University Faculty of Medicine

November 24, 2020

\begin{abstract}
An obstetric ultrasound of a multi-gravid mother at 37-week of gestation showed a female fetus with alobar holoprosencephaly, polydactyly, short ribs, narrow chest and short upper and lower extremity bones, consistent with Holoprosencephaly-polydactyly syndrome and Asphyxiating thoracic dystrophy overlap. Apgar score was 0 in the first and fifth minutes.
\end{abstract}

\section{Hosted file}

HPS-ATD overlapping syndromes CCR.pdf available at https://authorea.com/users/373595/ articles/494824-overlapping-holoprosencephaly-polydactyl-syndrome-and-asphyxiatingthoracic-dystrophy-an-incidental-finding-in-prenatal-ultrasound-screening-a-rare-casereport

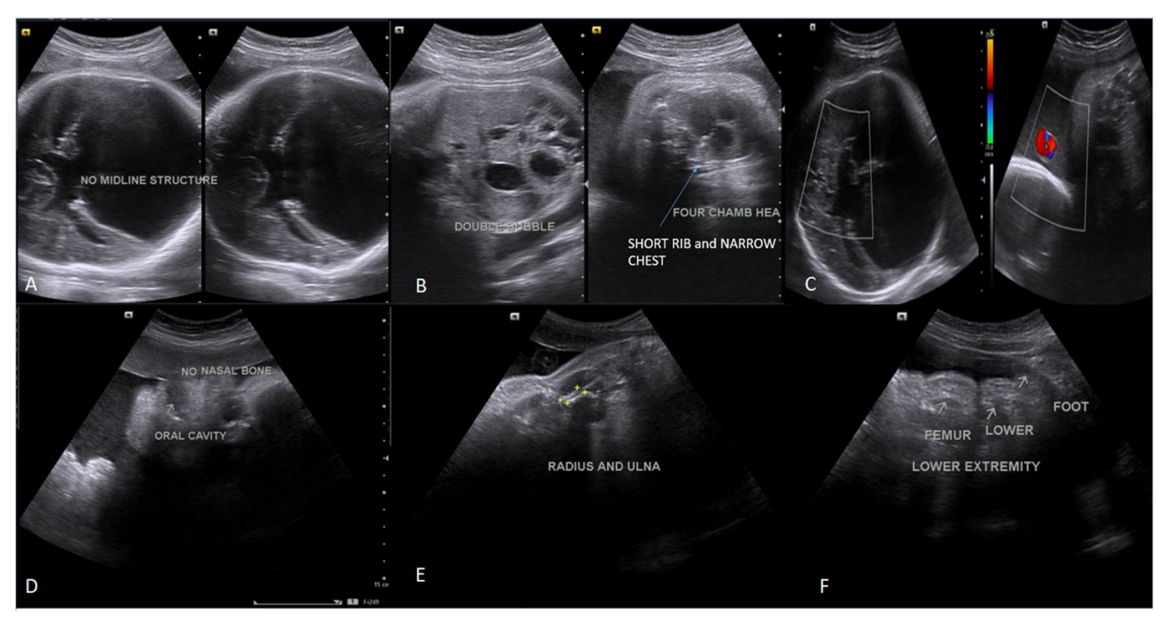



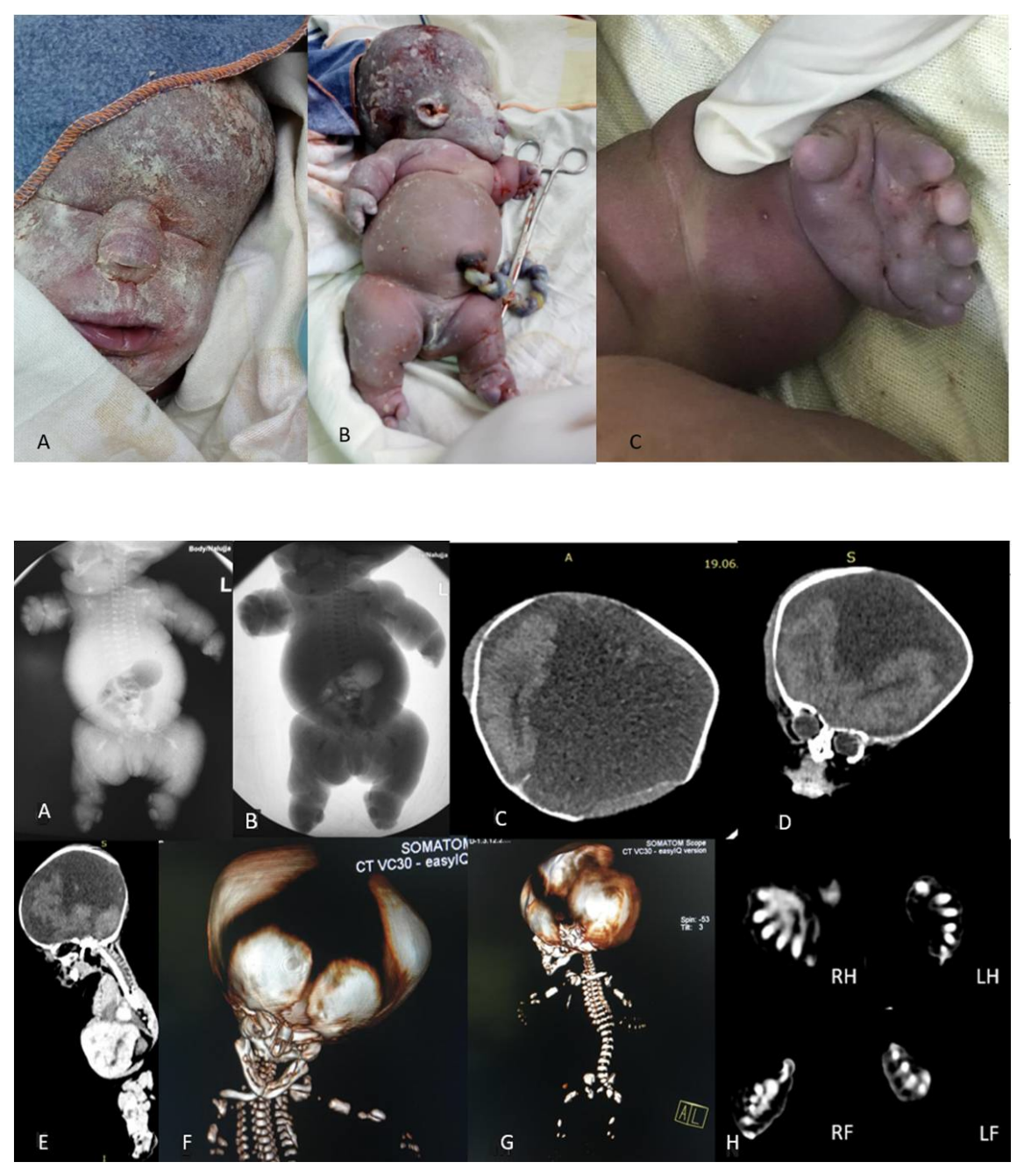